\title{
Mode Transition Analyses of the Attached Pressurized Module Cabin Air Loop with EcosimPro
}

\author{
J.A. Romera Perez \\ ESA/ESTEC TOS-MCT, The Netherlands \\ J. Persson, J. Witt \\ ESA/ESTEC MSM-MCE, The Netherlands
}

Copyright ( 2000 Society of Automotive Engineers, Inc.

\begin{abstract}
The change in mode status of the Attached Pressurized Module (APM), termed a mode transition, is due to the need of changing the APM configuration triggered by nominal or contingency events, i.e: initial system activation and further de/reactivation, payload activation, crew, ground or station initiated mode changes, etc.

Past simulations of the APM Cabin Air Loop, for individual operational modes, have been performed by Dornier. This paper presents the results of the hydraulic and thermal analyses of the APM Cabin Air Loop for mode transition with the new version of the European Space Agency (ESA) supported software EcosimPro. The range of analysis has now been extended to long duration simulation of transitions between modes, which was impractical in the past. The transitions cover both operational and non-operational modes, with rapid changes in boundary conditions, as heat loads, air and coolant mass flows, crew metabolic heat, International Space Station (ISS) supplied air interface temperature and relative humidity, etc.
\end{abstract}

\section{INTRODUCTION}

The APM is one of the major elements of the Columbus Orbital Facility (COF) programme, which represents the uropean contribution to the ISS (Fig.1). The APM is designed for multi-disciplinary Payload missions as micro-gravity, life science, earth observation, space science and technology disciplines.

The APM Environment Control and Life Support Subsystem (ECLSS) provides a pressurized environment during module transportation to orbit and for on-orbit operation when docked to the Space Station with related crew operations.

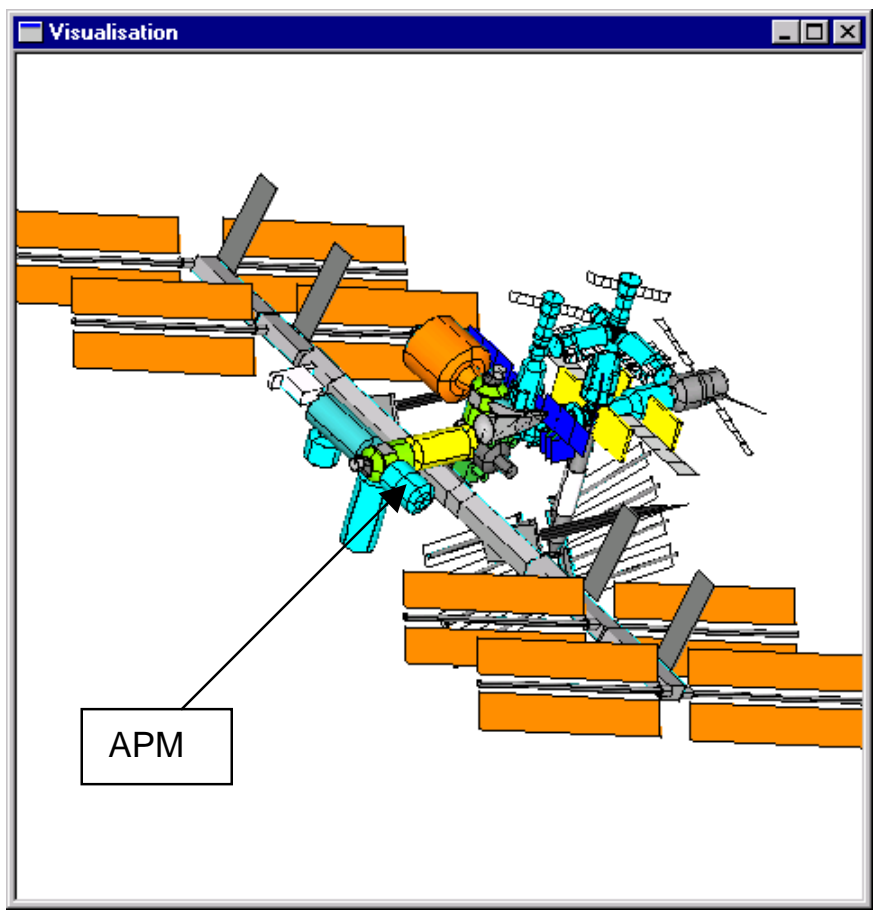

Figure 1: APM attached to the International Space Station (ESARAD model made by J.A. Romera)

The ECLSS provides the following functions:

- Atmosphere pressure monitoring and control (cabin depressurization, positive/negative pressure relief, total pressure monitoring, and $\mathrm{O}_{2}$ and $\mathrm{CO}_{2}$ partial pressure monitoring)

- Cabin Air Temperature and Humidity control (cabin ventilation, temperature and air humidity monitoring, air temperature control, air dehumidification and Inter Module Ventilation (IMV))

- Air revitalization (air sampling and air filtering) 
- Fire detection and suppression

- Vacuum and venting

- $\mathrm{N}_{2}$ supply

- Control of PAM shell and ECLSS heaters

\section{CABIN LOOP FUNCTIONAL DESCRIPTION}

The main objectives of the Cabin loop are:

a) collection of heat loads from crew and radiative and convective heat loads from surrounding surfaces (racks, end cones, standoffs) and transfer to the Thermal Control Subsystem (TCS) via the Condensing Heat Exchanger (CHEX).

b) collection of humidity produced by the crew and potential water leakages in the Cabin by the CHEX, and the transfer of the condensed water to the ISS for further re-use.

c) Revitalization of the Cabin air by returning the Cabin air to the ISS via the IMV, for $\mathrm{CO}_{2}$ removal and $\mathrm{O}_{2}$ partial pressure control.

The functional schematic of the Cabin Loop is shown in Fig. 2.

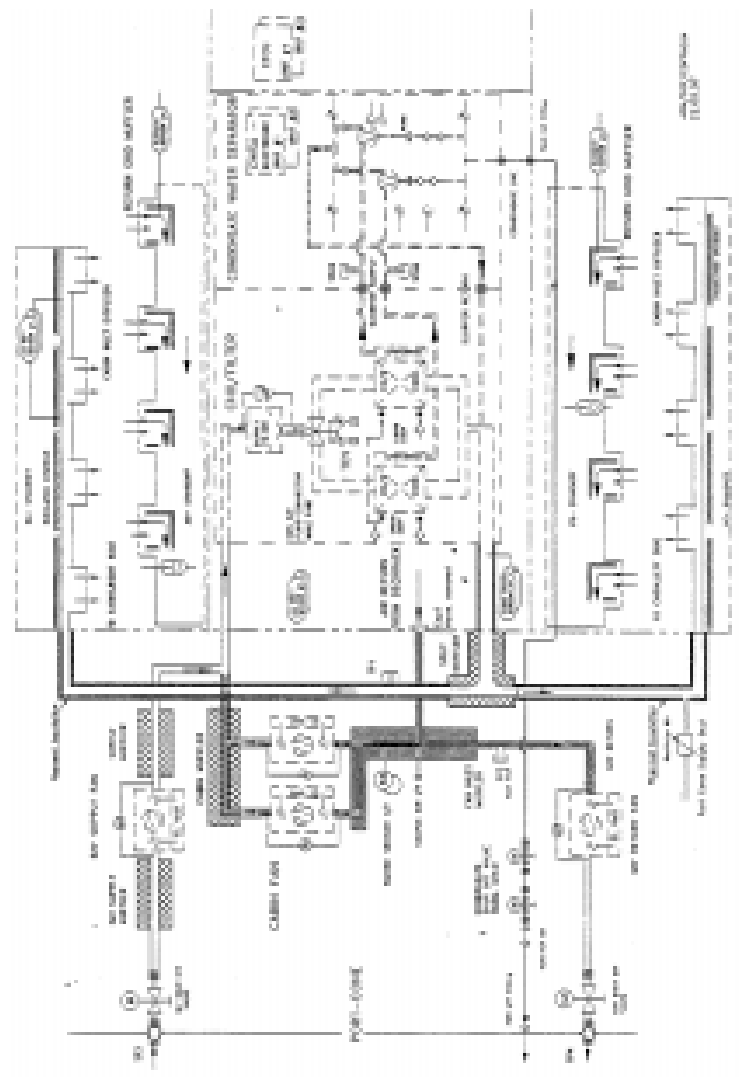

Figure 2: Cabin Loop Functional Schematic
The APM air is sucked from the deck-floor and partly given via IMV to ISS for revitalisation and partly pumped by the Cabin fan to the Cabin loop supply duct where it is mixed with the IMV supply air. Downstream the mixture of the IMV supply air with the air coming from the cabin fan is passed to the CHEX. After passing the filter the air flow is splitted and flows through the two parallel cores of the heat exchanger, from which one is cooled by the TCS water loop and the other is not cooled and serves as a bypass.

The mass flow ratio of the bypass and main-stream is controlled by the Temperature Control Valve (TCV). The TCV adjusts the air outlet temperature by mixing the cold main air stream with the warm bypass air. The valve is externally controlled by the Cabin Temperature Control Unit (CTCU), according to the selected Cabin air temperature set point (between 18 and $27^{\circ} \mathrm{C}$ ).

The air flowing out of the CHEX is distributed throughout the Cabin via the two branches of the Cabin loop supply ducting and the Cabin diffusers located in the upper cabin corners (four on each side alternating with lights). The minimum air flow rate is $51 \mathrm{~m}^{3} / \mathrm{hr}$ per diffuser.

The humidity produced by the crew is condensed in the active core of the CHEX. The condensate is collected in the slurper header, which interfaces to the slurper line. The water separator sucks an air-condensate mixture out of the CHEX through the slurper line. This mixture is separated into pure water and air. The water is driven through the condensate line to the ISS, and the air is returned to the loop at the outlet of the CHEX.

\section{DEFINITION OF TRANSITION MODES}

The APM Activation and Operations Modes Analysis (Ref.1), describes the APM mission in terms of phases and modes, and the initial activation of the APM. The mission phases describe the entire lifetime of the APM from Ground Processing, Launch and Ascent, Initialization, Routine Operations up to the APM Safe Disposal. Within the overall mission scenario and its associated phases the purpose of having APM modes is to provide a standard method for describing complex flight configurations and provide the ability to reliably operate the APM in those configurations. The main Operational APM modes are:

- Passive Mode

- Unberthed Survival Mode

- Berthed Survival Mode

- Stand-by Mode 
- Housekeeping

\section{- Support Mode Unmanned/Manned}

\section{- Nominal Mode Unmanned/Manned}

The change in mode status is termed a mode transition and is in response to a need to change the APM configuration status reflecting either a nominal or contingency event (see sketch below). Nominal mode transitions will be triggered by different events, e.g.: initial system activation, system de/reactivation, payload activation or crew, ground or station initiated mode changes

\section{SELECTION Of TRANSITION MODES}

From all possible permutations of transition modes as described in Ref.1 (see Fig. 3), four sequences of transitions have been retained for further analyses with EcosimPro:

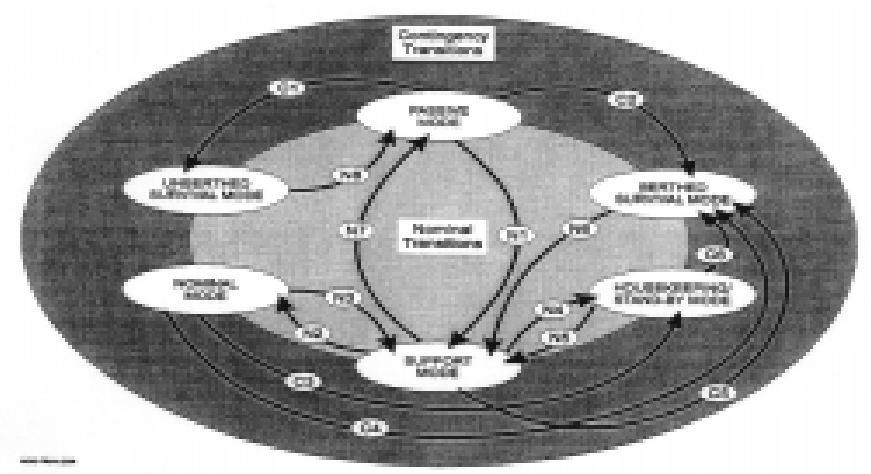

Figure 3: Modes Transition

Case 1:

Nominal Manned (3 crew) -> Support Unmanned (No crew) -> Housekeeping (2 crew) -> Support Manned (3 crew) -> Nominal Manned (3 crew)

\section{Case 2:}

Nominal Manned (3 crew) -> Standby (No crew) -> Support Manned (3 crew) -> Nominal Manned (3 crew)

\section{Case 3:}

Nominal Manned (3 crew) -> Berthed Survival (No crew) -> Support Manned (3 crew) -> Nominal Manned (3 crew)
Case 4:

Nominal Manned (3 crew) -> Nominal Unmanned (No crew) -> Nominal Manned (3 crew)

As no timing has been specified to each mode, we have assumed durations ranging from 4 hours (Support Unmanned and Manned and Housekeeping), to 8 hours (Berthed) and to 16 hours (Nominal Unmanned).

In order to stress the system, crew metabolic activity is always set to maximum (corresponding to heavy work figures of Ref. 2, with the exception of housekeeping mode where they correspond to the little work figures). Because the way the crew component is treated in EcosimPro, the total metabolic heat generated (sensible plus latent heat dissipation) is given as input. EcosimPro formulation of the crew component computes the sensible and latent heat produced, based on the environmental variables of the cabin.

\section{EcosimPro APM Cabin Air Loop Model}

EcosimPro is a completely new version of an original software tool developed within the framework of a contract with ESA for simulation of environmental control and life support systems on manned spacecrafts. The first version ran under Unix system and was specially created with a dedicated and comprehensive library of components, which included pipelines, valves, fans, heat exchangers, PID controllers, crew, etc.

The Cabin Air Loop model of the APM was originally created by Dornier (Ref. 3) as part of the design activities of the APM ECLS Subsystem.

Instabilities and convergence problems associated to simulations with rapid changes in boundary conditions (mass flow, metabolic heat, crew number, etc.) were found during first trials on Mode transitions. Some of those problems were connected to mathematical accuracy of the software solver, which induced very long computing time (in the order of four hours of CPU per each hour of simulation time). Others, as for example those dealing with the stop of fans, were due to inherent model configuration fault.

At that time the software developer Empresarios Agrupados International (EAI), was working with the beta version of the new EcosimPro for PC, which offered a much faster and efficient solver (up to 10 times improvement as compared to the Unix computation speed).

Before the new version could be used for the APM Cain Loop Air model, some tasks already foreseen under ESTEC Contract 11044/94 (Adaptation of current ECLS 
components to the new ECOSIM 3.0), had to be performed which requested the technical support of EAI:

- Conversion, update and validation of the ECLSS Library

- Conversion of DORNIER's model, as there is no model commonality from old to new EcosimPro versions

- Validation of the APM converted model with respect to previous Unix model

- Upgrade of the APM model to improve its mathematical stability and accuracy in fast transient cases, and its adaptation to special mode

The sketch of the modified APM model using SmartSketch (flow-sheet editor of EcosimPro) is shown below:

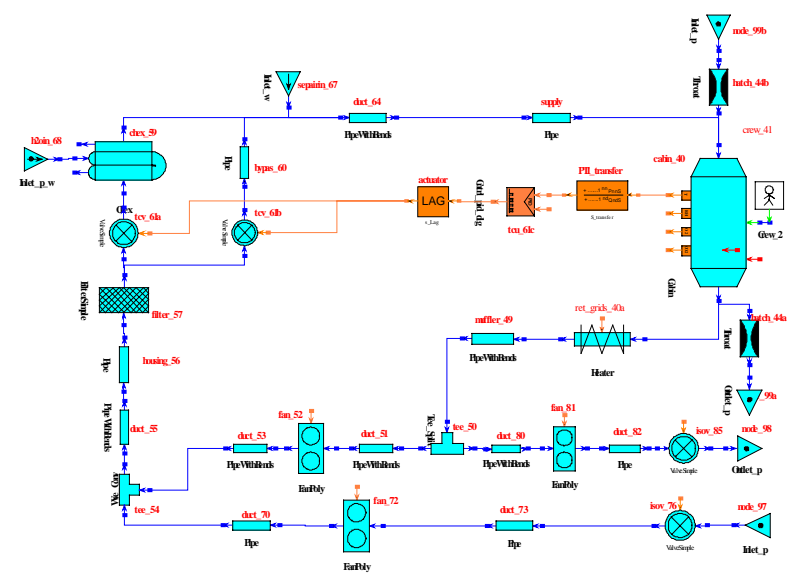

Figure 4: APM Cabin Air Loop model

The upgraded APM model has more than 1300 variables and more than 500 equations.

\section{APM MODEL UPGRADES}

As it was mentioned before, the model had to be converted to the new version format, since there is no compatibility of models between versions. That conversion not only affected the name of the variables (most of the variables have a modified name in the new version), but also affected to some components which were modified to improve the solution accuracy, stability and speed.

A more detailed explanation on the implemented modifications and changes follows:

- crew_41 component:
A small thermal capacity has been assigned to the cloth to avoid unstable solver solutions induced by the crew cloth temperature.

To avoid a different temperature of the crew when leaving the cabin and returning again (Unmanned phases), the values of the derivatives of the skin, core and cloth temperatures are set equal to zero.

The formulation has been protected against negative velocity of the air flow (flow from the cabin outlet to the cabin inlet): vel_air**0.67 has been passed to abs(vel_air) ${ }^{\star *} 0.67$

- fan_52,fan_72,fan_81 components:

The fan power and pressure head curves are defined by adjusted polynomia to avoid discontinuities in the derivatives when linear interpolation is used in the original curves defined by tables.

- PID component:

Some errors were corrected from previous versions of the digital PID controller.

- $\quad$ hatch_44 component:

The old hatch_44 has a very large area (diameter $=1.2$ $\mathrm{m}$ ), and the calculated mass flow based on pressure differences between the cabin and the outlet node is very unstable, because very small pressure differences can create huge flows. The hatch component has a parameter in order to try to stabilise the calculation (dplam: pressure drop for laminar flow). If the pressure difference is less than dplam, then the pressure drop is assumed to change linearly with respect to the mass flow (this has an stabilising effect). The problem with the old APM model was that the dplam parameter had been assigned a very low value, and the calculated value of the mass flow through the hatch had spikes, resulting in cabin temperature modification because of the mixing of the hatch air with the cabin air. To improve the stability of the solution a higher dplam value has been selected (10 Pa).

To account for the reverse flow two hatch components (hatch_a and hatch_b) replaces the old hatch_44. Each hatch component only allows the flow in one direction (hatch_a: cabin exit and hatch_b: cabin inlet).

- div_58,jun_62 components:

Divisor and junction components have disappeared because multiple connections are now automatically managed by connecting prefixes (SUM, EQUAL, SUM IN, EQUAL OUT) in the declaration of the port variables. 
- h2oout_69, node_98, node_99 components:

Outlet boundary conditions have disappeared. Now, the outlet pressure is being specified directly as a boundary condition in the partition.

\section{- Actuator component:}

The digital controller obliges continuous restarts of the integration algorithm at each sampling interval. The algebraic equations have to be satisfied previously to each restart, but the non-linear equation solver of the old version was not very efficient. A solution, which has been implemented in the upgraded model, is a valve actuator of very short time constant, to avoid step movements of the control valves.

\section{- $\quad$ Fluid components}

Most of the fluid components in the UNIX version where using an average density:

$$
\begin{aligned}
& \text { rho_avg }=0.5^{\star}\left(f \_ \text {in.rho }+f \_o u t . r h o\right) \\
& \text { f_in.p-f_out.p = zeta }{ }^{\star} f \_i n . w^{\star} a b s\left(f \_i n . w\right) /\left(r h o \_a v g{ }^{*} A^{* *} 2\right)
\end{aligned}
$$

That created an implicit algebraic loop in all the components, because the outlet density depends on the outlet pressure. If we take into account that the pressure losses are very small, the average density is practically equal to the inlet density, and then the outlet pressure can be explicitly calculated:

$$
f \_ \text {out.p }=f \_ \text {in.p -zeta*f_in.w*abs }\left(f \_ \text {in.w }\right) /\left(f \_ \text {in.rho * } A^{* *} 2\right)
$$

\section{- Variable names}

Most of the variables that have changed names are the masses and the specific heats of the solid parts of the fluid components. These variables were previously named as: m_met (mass of metal parts), or m_mat (mass of material) or some other names. Now, there is a more consistent naming, i.e. m_dry (dry mass of the component), and cp_dry (specific heat of the dry mass).

\section{- Include file}

The main concept in EcosimPro is the Library instead of the file. This has eliminated the need of having to include multiple files when defining the models. The new EcosimPro does not have facilities for including files. Most of the variables in the std_b file have been incorporated into the data of the APM model component itself.

\section{ANALYSIS ASSUMPTIONS}

The purpose of the analyses is to demonstrate the performance of the ECLSS in the worst scenarios for the selected transition modes. In order to stress the transition scenarios some very conservative assumptions have been taken:

- Selection of minimum/maximum Cabin air set points, with maximum crew metabolic heat.

- The heat loads to the ECLSS as given in Ref. 4 have been distributed as follows:

- $\quad$ Radiative heat loads are applied to the Cabin wall

- Cabin air heat loads are applied to the Cabin air

- The convective heat transfer coefficient Cabin wallair (cabin_40.h_conv) for forced cooling (fans on) is set to $1 \mathrm{~W} / \mathrm{m} 2 \mathrm{~K}$. When fans are off (Berthed Survival mode), the convective heat transfer coefficient has been set equal to a low value of $0.01 \mathrm{~W} / \mathrm{m} 2 \mathrm{~K}$.

- The $\Delta \mathrm{p}$ for the filter has been set to its End of Life value of $265 \mathrm{~Pa}$ at $.158 \mathrm{~kg} / \mathrm{s}$.

- CHEX coolant flow has been set to $565 \mathrm{~kg} / \mathrm{h}$ for Nominal modes with $130 \mathrm{~kg} / \mathrm{h}$ for Support and Housekeeping modes.

- $\quad$ The IMV air conditions have been set constant to 18 ${ }^{\circ} \mathrm{C}$ with a relative humidity of $50 \%$. The analyses are carried out in such a way that Sensible and Latent heat through the IMV Interface is not limited. In previous analyses the IMV supply conditions were always trimmed to get a sensible heat transfer of $+/-$ $220 \mathrm{~W}$. Initial attempts to avoid the latent heat exchange between the IMV supply air and the cabin (by establishing the equality of relative humidity values in the experiment boundary declaration segment) led to non-convergence problems with the EcosimPro solver. It was decided therefore to allow the possibility of latent heat exchange depending on the conditions in the cabin.

- $\quad$ Cabin hatch is always open and represented by two one-way hatch components

- $\quad$ Slurper suction is stopped in the Berthed mode (fans off).

- Crew metabolic load is defined as the sum of the sensible and latent heat figures for heavy work in Ref. 2. Basal metabolic heat requested by the crew component in EcosimPro is given as the metabolic heat (sensible + latent) of the sleep activity. All cases are analyzed with a clo factor of 0.62 corresponding to crew with fitted trousers and longsleeve shirt. 


\section{INPUT PARAMETERS}

Table 1 below provides the main input data for the different analysed cases.

\begin{tabular}{|c|c|c|c|c|c|c|c|}
\hline Mode & A & B & C & D & $\mathrm{E}$ & $\mathrm{F}$ & $G$ \\
\hline $\begin{array}{l}\text { Duration } \\
\text { (hr) }\end{array}$ & 8 & 16 & 4 & 4 & 4 & 4 & 8 \\
\hline $\begin{array}{l}\text { Crew } \\
\text { number }\end{array}$ & 3 & 0 & 3 & 0 & 2 & 0 & 0 \\
\hline $\begin{array}{l}\text { Activity } \\
\text { (W) }\end{array}$ & $\begin{array}{c}234 \\
\text { (a) }\end{array}$ & 0 & $\begin{array}{l}234 \\
\text { (a) }\end{array}$ & 0 & $\begin{array}{l}132 \\
\text { (b) }\end{array}$ & 0 & 0 \\
\hline $\begin{array}{l}\text { Basal } \\
\text { (W) }\end{array}$ & 88 & 0 & 88 & 0 & 88 & 0 & 0 \\
\hline $\begin{array}{l}\text { Cabin } \\
\text { set point } \\
\left({ }^{\circ} \mathrm{C}\right)\end{array}$ & $\begin{array}{l}18 \\
27 \\
\text { (c) }\end{array}$ & 18 & $\begin{array}{l}27 \\
(d) \\
18\end{array}$ & 18 & 27 & 18 & $\begin{array}{l}\text { No } \\
\text { ctrl }\end{array}$ \\
\hline $\begin{array}{l}\text { Radiat. } \\
\text { heat load } \\
\text { to cabin } \\
\text { wall } \\
\text { (W) }\end{array}$ & 915 & 915 & 536 & 416 & 404 & 350 & 0 \\
\hline $\begin{array}{l}\text { Heat } \\
\text { load to } \\
\text { Cabin air } \\
\text { (W) }\end{array}$ & 700 & 700 & 700 & 389 & 489 & 389 & 0 \\
\hline $\begin{array}{l}\Delta \mathrm{p} \text { filter } \\
(\mathrm{Pa})\end{array}$ & 265 & 265 & 265 & 265 & 265 & 265 & 0 \\
\hline $\begin{array}{l}\text { Coolant } \\
\text { flow } \\
(\mathrm{Kg} / \mathrm{h})\end{array}$ & 565 & 565 & 130 & 130 & 130 & 130 & 0 \\
\hline $\begin{array}{l}\text { Fans } \\
\text { Config. }\end{array}$ & ON & ON & ON & ON & ON & ON & Off \\
\hline $\begin{array}{l}\text { IMV air } \\
\text { supply } \\
\text { temp. } \\
\left({ }^{\circ} \mathrm{C}\right)\end{array}$ & 18 & 18 & 18 & 18 & 18 & 18 & 18 \\
\hline $\begin{array}{l}\text { IMV air } \\
\text { supply } \\
\text { R.H. (\%) }\end{array}$ & 50 & 50 & 50 & 50 & 50 & 50 & 50 \\
\hline
\end{tabular}

Table 1: Input Parameters

Notes:

A: Nominal, B: Nominal Unmanned, C: Support Manned, D: Support Unmanned, E: Housekeeping, F: Standby, G: Berthed Survival. a) heavy work activity, b) little work activity, c) case 4 last mode, d) case $14^{\text {th }}$ mode

\section{MAIN RESULTS}

\section{- CASE 1}

The ECLSS is able to maintain the temperature of the Cabin close to the set point during all phases, within the tolerance of $+/-1{ }^{\circ} \mathrm{C}$, irrespective of the set point selected (18 and $27^{\circ} \mathrm{C}$ ).

Due to the assumption of application of the radiative heat loads to the Cabin wall, its temperature increases to a maximum of $37^{\circ} \mathrm{C}$. We have to note that the Cabin wall component in EcosimPro is only coupled to the Cabin air, and therefore it has no heat leak paths to the pressurised vessel wall or to any other item, which could reduce its temperature level.

The air dew point temperature in the Cabin is always maintained in the range $4.4{ }^{\circ} \mathrm{C}$ to $15.5^{\circ} \mathrm{C}$.

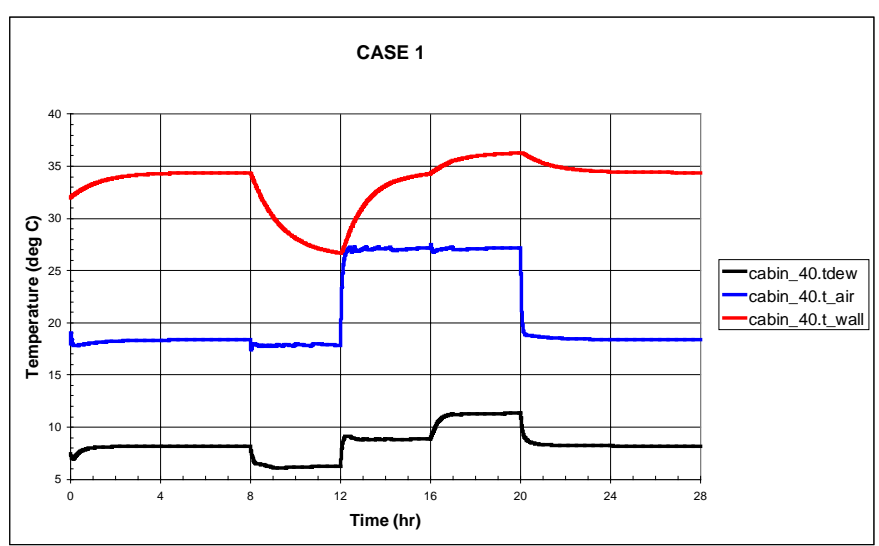

The relative humidity in the Cabin is always inside the

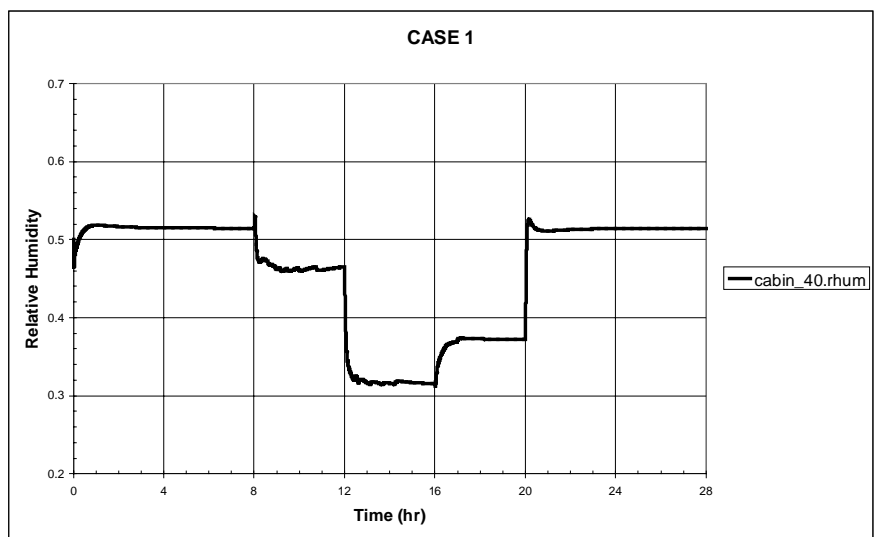

required range $25 \%$ to $70 \%$. 
The bypass is fluctuating between $5 \%$ and $95 \%$, as we could expect from the big heat loads into the Cabin, and the set selected set points $\left(18^{\circ} \mathrm{C}\right.$, respectively $\left.27^{\circ} \mathrm{C}\right)$.

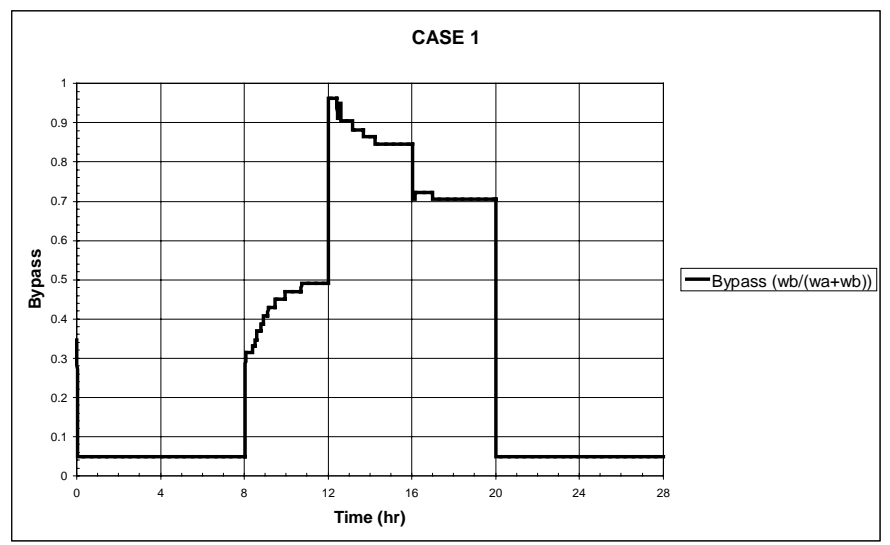

The CHEX water outlet temperature is close to $9{ }^{\circ} \mathrm{C}$ for an inlet of $5{ }^{\circ} \mathrm{C}$ in the Nominal Manned phase with 565 $\mathrm{Kg} / \mathrm{hr}$ of flow rate. The water outlet temperature reaches $15^{\circ} \mathrm{C}$ in the initial transient period to the Support Unmanned phase, when the water mass flow is reduced to $130 \mathrm{Kg} / \mathrm{hr}$.

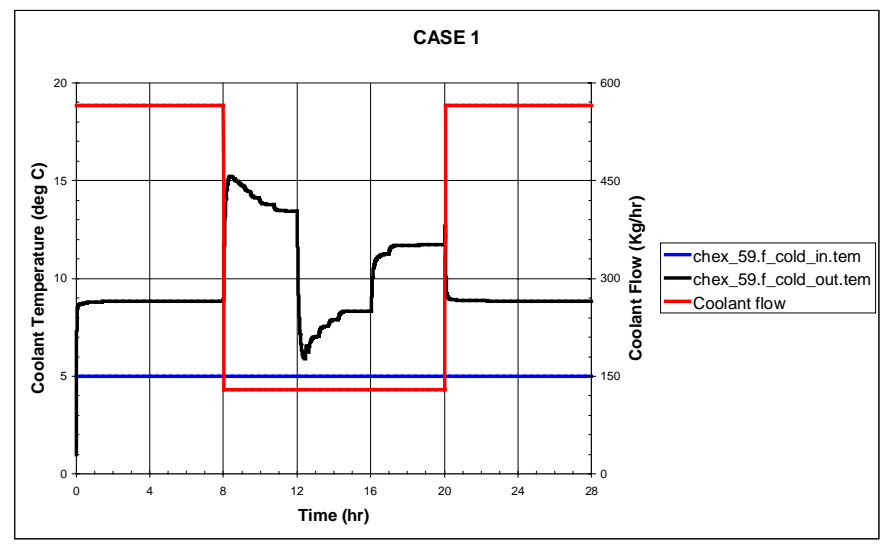

A maximum of $3 \mathrm{KW}$ is exchanged in the CHEX.

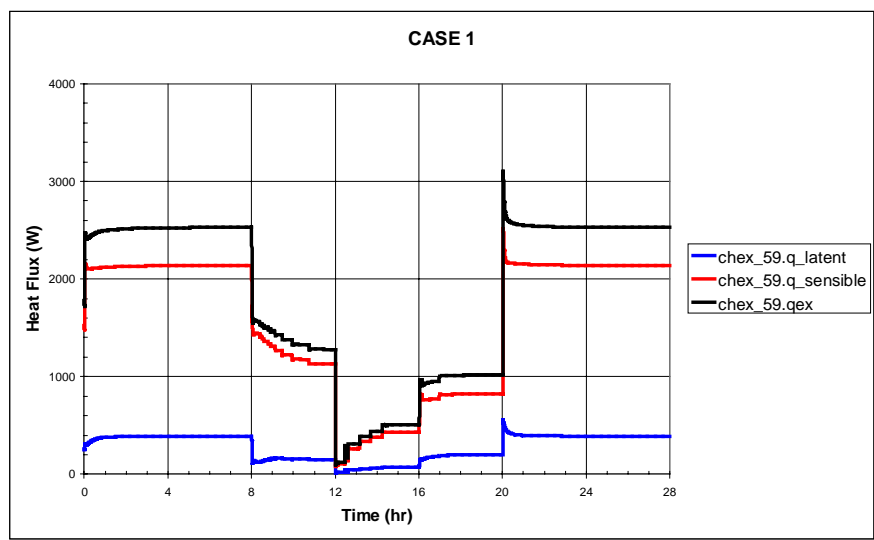

Crew Thermal sensation is in the band between neutral and slightly warm for all phases, with the exception of the Support Manned phase, where it is close to warm. The reasons are the high heat loads, combined with a high selected Cabin set point of $27^{\circ} \mathrm{C}$.

The thermal discomfort is in the band between comfortable and slightly uncomfortable, with the exception again of the Support manned phase, where it jumps to the next band (between slightly uncomfortable and uncomfortable).

Sensible heat exchanged with ISS through the interface is well outside the requirements of $+/-220 \mathrm{~W}$, specially for the Housekeeping and Support manned phases where the selected Cabin air temperature is $27^{\circ} \mathrm{C}$, with an IMV supply temperature of $18^{\circ} \mathrm{C}$. The Latent heat exchanged with the ISS varies between $150 \mathrm{~W}$ and -330 W.

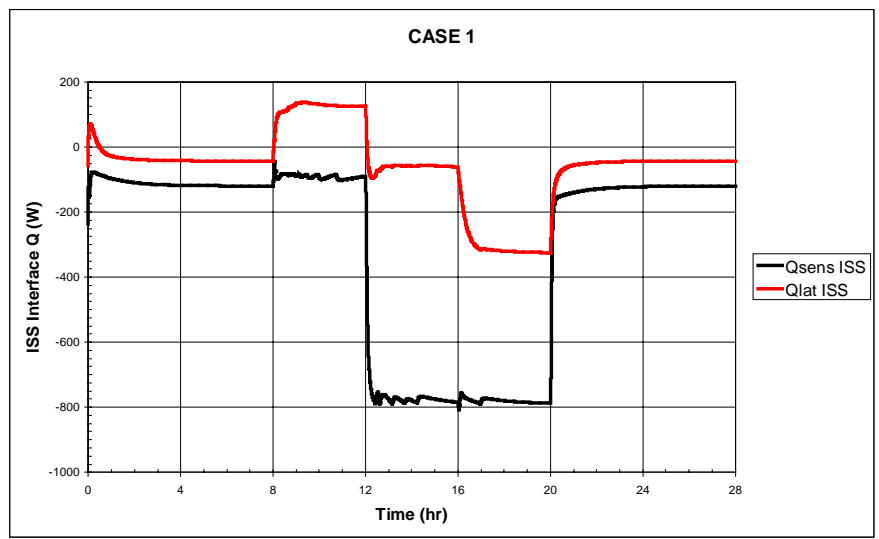

The dew point temperature of the IMV supply is constant as we expect from constant temperature and relative humidity conditions of the supply air. Return air dew point dew varies upon the cabin temperature and humidity generated by crew:

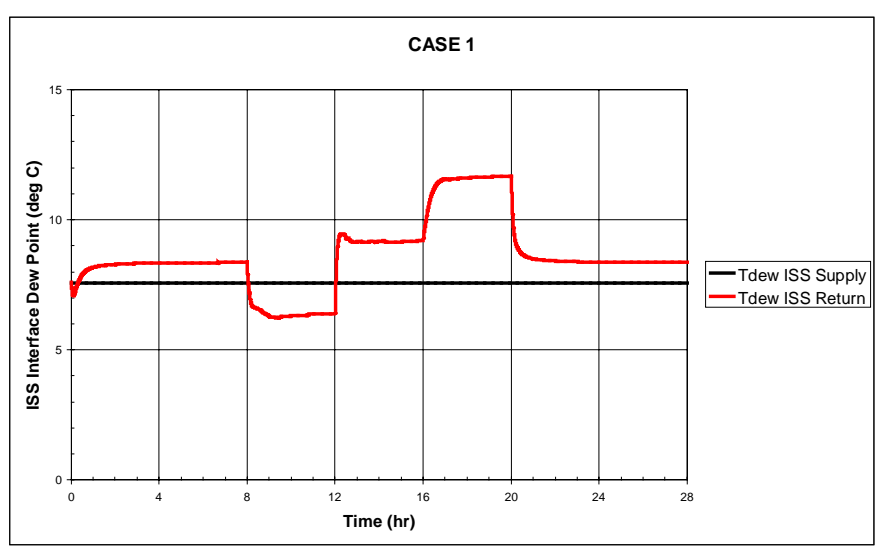




\section{- CASE 2}

The ECLSS is able to maintain the temperature of the Cabin close to the set point during all phases $\left(18 \pm 1^{\circ} \mathrm{C}\right)$, with the exception of a small period of time in the transition from Stanby to the Support Manned phase. During that time the Cabin air temperature is marginally out of the set point tolerance.

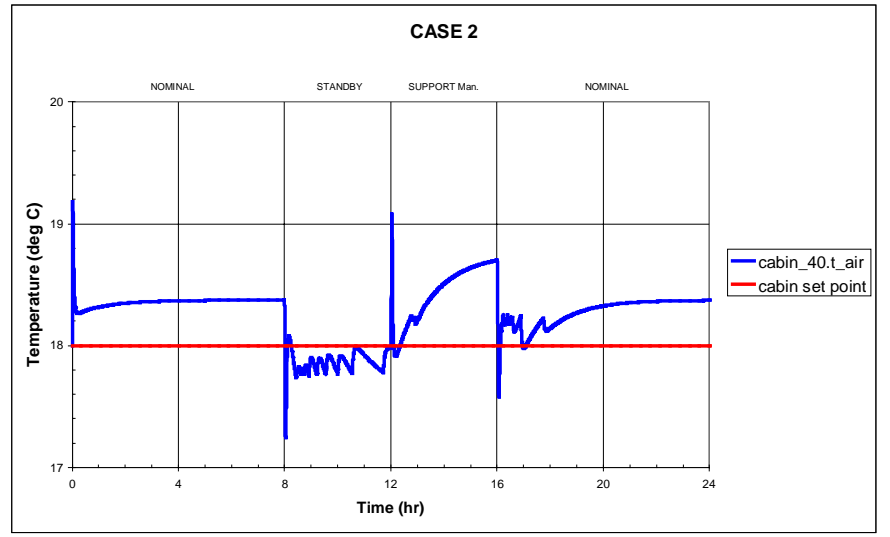

The air dew point temperature in the Cabin is always maintained in the range $4.4^{\circ} \mathrm{C}$ to $15.5^{\circ} \mathrm{C}$.

The Cabin wall reaches maximum temperatures close to $35^{\circ} \mathrm{C}$.

The relative humidity in the Cabin is always inside the required range $25 \%$ to $70 \%$.

The bypass is fluctuating between $5 \%$ (high heat loads and low set point), and $54 \%$ (standby with reduced heat loads).

CHEX water outlet temperature is about $15{ }^{\circ} \mathrm{C}$ for an inlet of $5^{\circ} \mathrm{C}$ in the Standby phase with $130 \mathrm{Kg} / \mathrm{hr}$ of flow rate. That outlet temperature increases to about $17.5^{\circ} \mathrm{C}$ in the Support manned phase with the same low flow rate.

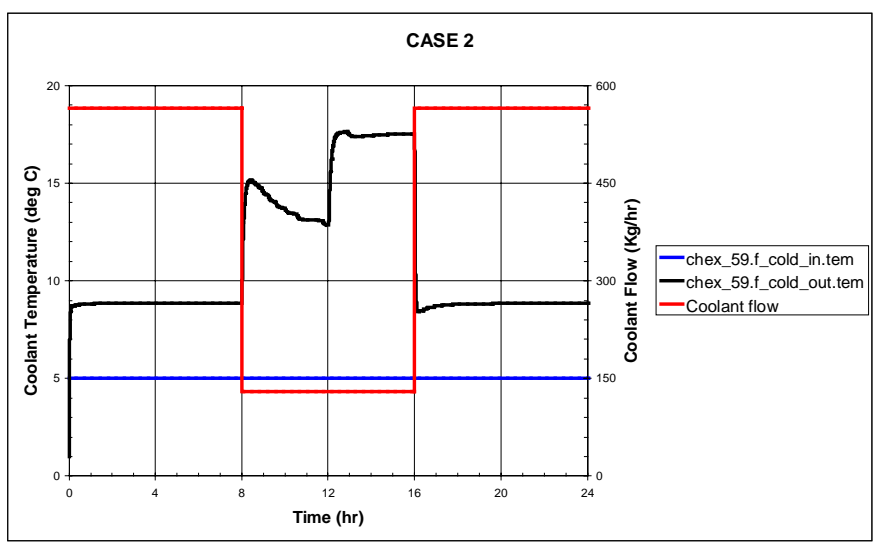

A maximum of $2.5 \mathrm{KW}$ is exchanged in the CHEX.

Crew Thermal sensation is in the band between neutral and slightly warm for all phases.

The thermal discomfort is in the band between comfortable and slightly uncomfortable.

Sensible heat exchanged with ISS through the interface is inside required values of $+/-220 \mathrm{~W}$ (selected Cabin air temperatures are equal to the ISS supply temperature). The Latent heat exchanged with the ISS varies between $135 \mathrm{~W}$ and $-220 \mathrm{~W}$.

\section{- CASE 3}

This is a peculiar transition analysis because it includes a Berthing Survival phase (assumed to last 8 hours), where the main items of the ECLSS (fans) are switched off.

We have to consider that the Cabin wall in the EcosimPro model, representing the Rack walls facing the crew working volume of the APM Cabin, is only connected to the Cabin air by means of a forced convective heat transfer coefficient. During Berthing there is no air circulation in the Cabin, and therefore if we continue applying the amount of heat loads to the Cabin wall as specified in Ref.4 (1148 W), the temperatures which would be reached by the Cabin wall would be unrealistic (in the order of $150{ }^{\circ} \mathrm{C}$ ).

It has been assumed therefore, that the Cabin wall heat loads during Berthing are $0 \mathrm{~W}$, and the forced convective heat transfer coefficient is very low (0.01 $\mathrm{W} / \mathrm{m} 2 \mathrm{~K})$.

With those assumptions we obtain a maximum Cabin air temperature of $23^{\circ} \mathrm{C}$, during the Berthing phase. The Cabin air temperature, during the Support Manned phase which follows Berthing, stabilises around $18^{\circ} \mathrm{C}$, within the $\pm 1{ }^{\circ} \mathrm{C}$ set point tolerance.

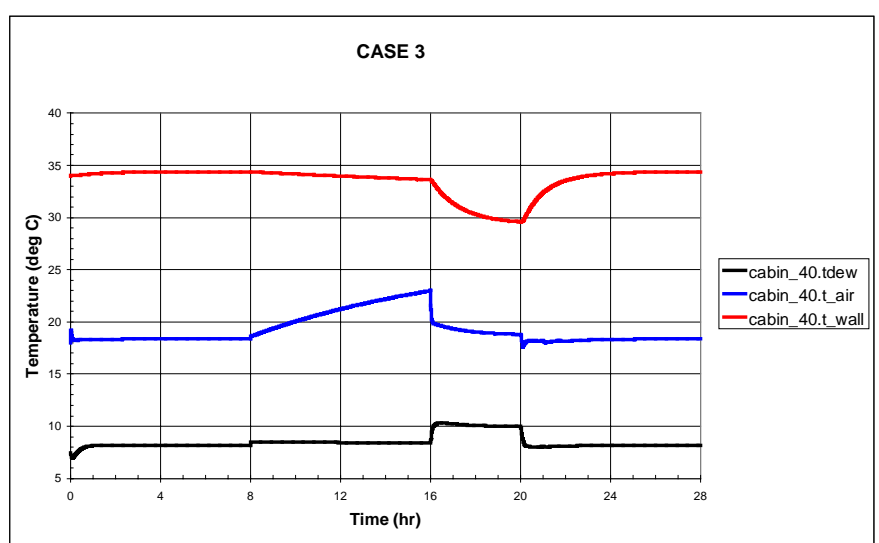


The air dew point temperature in the Cabin is always maintained in the range $4.4^{\circ} \mathrm{C}$ to $15.5^{\circ} \mathrm{C}$.

The Cabin wall reaches a maximum temperature close to $35^{\circ} \mathrm{C}$.

The relative humidity in the Cabin is always inside the required range $25 \%$ to $70 \%$. During Survival the relative humidity will slowly decay as there is no crew presence in the Cabin.

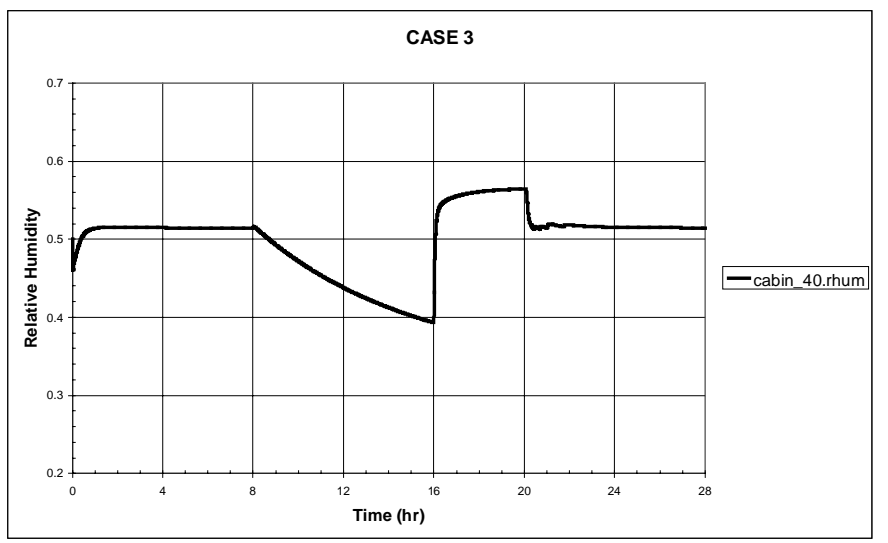

With fans switched off there is a small air exchange through the hatch produced by a pressure difference (different temperatures between cabin inside and outside) as seen below:

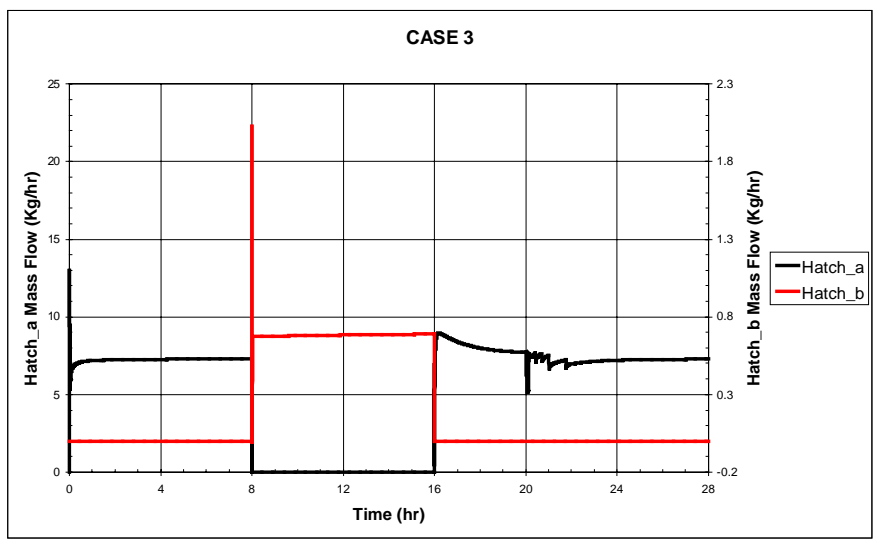

The bypass is always around the minimum value of $5 \%$, because the high heat loads and the minimum set point selected.

CHEX water outlet temperature rises to $18^{\circ} \mathrm{C}$ during the Support manned phase, with a low flow rate of 130 $\mathrm{Kg} / \mathrm{hr}$, returning to a value close to $9^{\circ} \mathrm{C}$ when coolant flow is re-established.

A maximum of $2.6 \mathrm{KW}$ is exchanged in the CHEX.

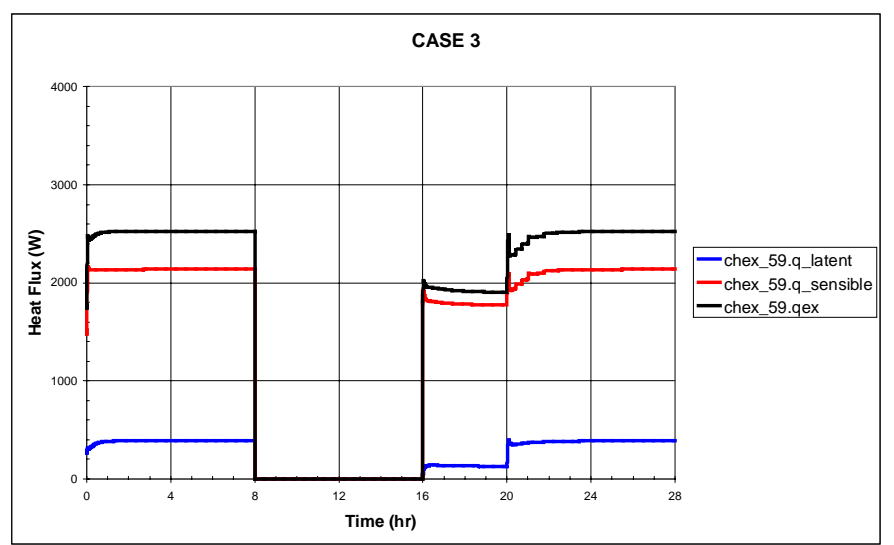

Crew Thermal sensation is in the band between neutral and slightly warm for all phases.

The thermal discomfort is in the band between comfortable and slightly uncomfortable.

Sensible heat exchanged with ISS through the interface is inside required values. The Latent heat exchanged with the ISS reaches a minimum of $-250 \mathrm{~W}$. During Berthing with no air circulation and no water produced by crew, Latent heat is null.

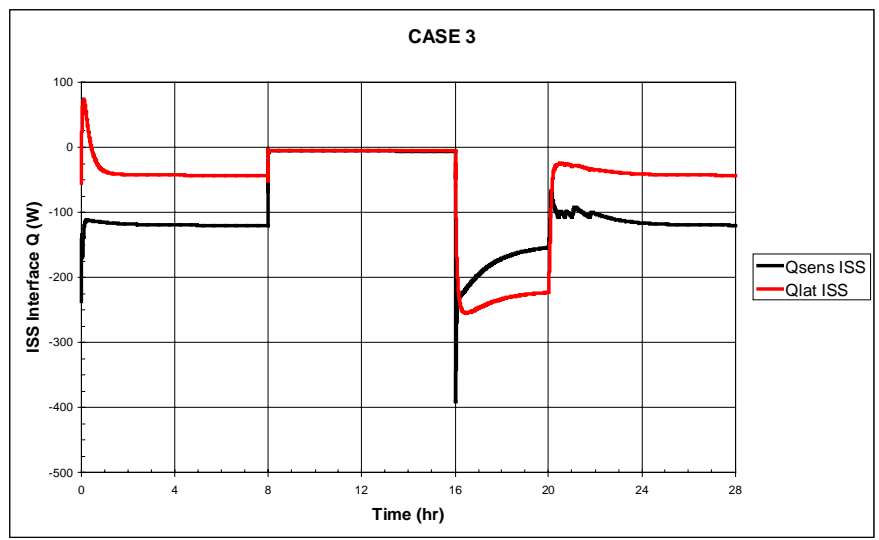

\section{- CASE 4}

This case represents the Routine operations with a Nominal Manned phase of 8 hours, followed by a Nominal Unmanned phase of 16 hours, followed by a Nominal Manned phase of 8 hours, and so on.

The ECLSS is able to maintain the temperature of the Cabin close to the set point during all phases $\left(18 \pm 1^{\circ} \mathrm{C}\right.$ in the first Nominal manned and further unmanned phases, and $27 \pm 1^{\circ} \mathrm{C}$ in the second Nominal manned phase). 
The air dew point temperature in the Cabin is always maintained in the range $4.4^{\circ} \mathrm{C}$ to $15.5^{\circ} \mathrm{C}$.

The Cabin wall reaches maximum temperatures close to $42{ }^{\circ} \mathrm{C}$, due to the high heat loads and high set point selected $\left(27^{\circ} \mathrm{C}\right)$, in contrast to $18^{\circ} \mathrm{C}$ of previous cases.

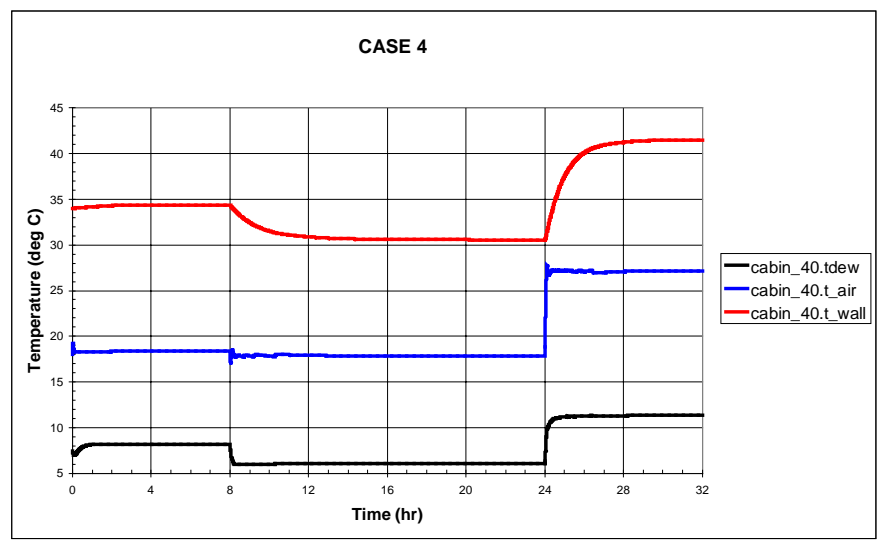

The relative humidity in the Cabin is always inside the required range $25 \%$ to $70 \%$.

The bypass is fluctuating between $5 \%$ (first Nominal manned with set point at $18{ }^{\circ} \mathrm{C}$ ), $40 \%$ (Nominal unmanned), to $60 \%$ (second Nominal manned with set point at $27^{\circ} \mathrm{C}$ ).

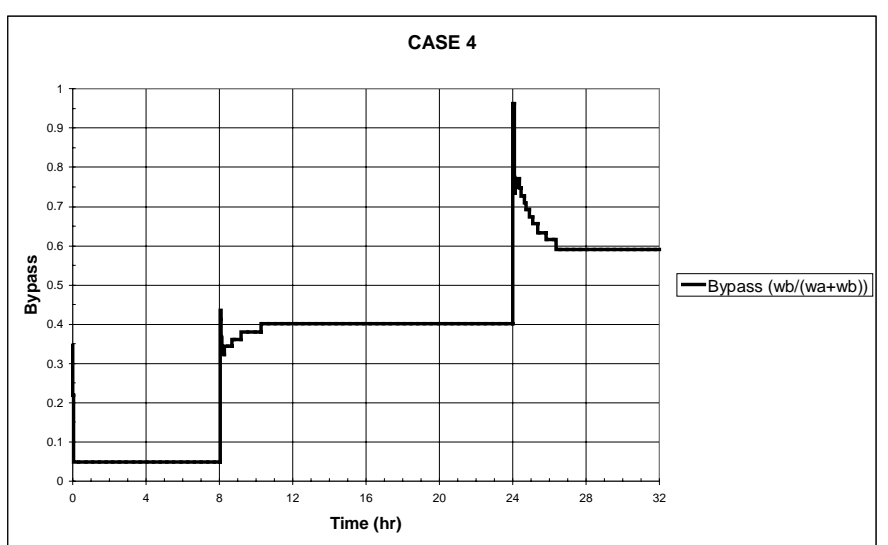

CHEX water outlet temperature ranges between 7 to 9 ${ }^{\circ} \mathrm{C}$ for an inlet of $5{ }^{\circ} \mathrm{C}$, at $565 \mathrm{Kg} / \mathrm{hr}$ of flow rate.

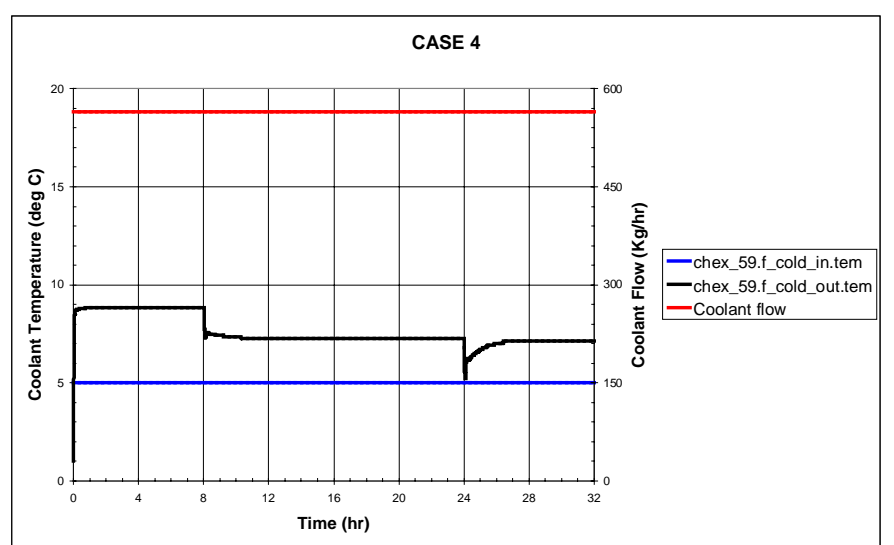

A maximum of $2.5 \mathrm{KW}$ is exchanged in the CHEX.

Crew Thermal sensation is in the band between neutral and slightly warm for the first Nominal manned phase, increasing to warm in the second Nominal phase because the high set point of $27^{\circ} \mathrm{C}$ and high heat loads. The thermal discomfort is in the band between comfortable and slightly uncomfortable, for the first Nominal manned phase, reaching the uncomfortable limit in the second Nominal phase.

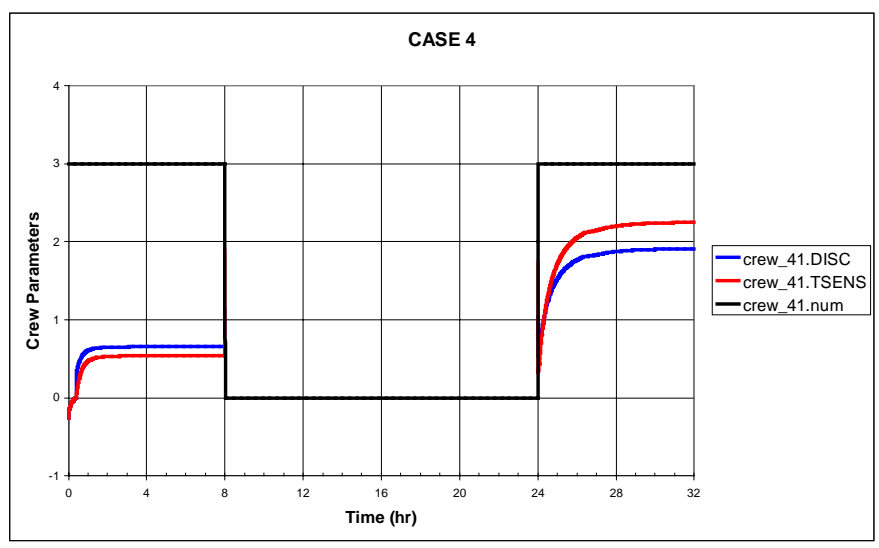

Sensible heat exchanged with ISS through the interface is outside the required values of $+/-220 \mathrm{~W}$, when the selected Cabin air temperature is very different from the ISS supply temperature (second Nominal manned phase, with selected Cabin set point of $27^{\circ} \mathrm{C}$ ). The Latent heat exchanged with the ISS varies between 135 $\mathrm{W}$ and $-340 \mathrm{~W}$. 


\section{CONCLUSIONS}

The ECLSS is able to maintain the required environment in the APM Cabin as demonstrated by the analyses. Slight non-compliances are found in the Operations under reduced performance phases (Support Unmanned and Berthing).

Sensible heat exchanged through the interface with the ISS is non-compliant specially when the selected set point is far from the ISS air supply conditions.

Latent heat exchanged is always out of requirements, as the present model does not consider any feedback effect of the return air conditions on the supply ones.

Additional coupling of the Ecosimpro Cabin wall to other elements of the APM Cabin (pressurised shell, MLI, MDPS, space) through available thermal port, would provide a more realistic model representation of heat transfer paths and therefore more accurate results.

Ecosimpro is found to be a very valuable and fast tool for long duration transient analyses.

\section{ACKNOWLEDGE}

Special thanks to Mr. R. Perez Vara (EAI) for his technical support and advise with the conversion of the ECLSS Library and APM model to the new version of Ecosimpro.

The work reported here was supported by the Thermal section of COF Project at ESTEC, and supervised by J. Persson and J. Witt.

\section{REFERENCES}

Ref.1. APM Activation and Operations Modes Analysis. COL-RIBRE-AN-0010. Issue 1.

Ref.2. Manned Space Flight Human Factors Engineering Handbook. MS-ESA-HB-013. Issue 1.

Ref.3. Hydraulic and Thermal Analysis of the APM Cabin Ventilation Loop. COL-DOR-TN-0232 Iss.3 Rev 3.

Ref.4. Flight Configuration Thermal Budget Report. COL-RP-Al-0118. Issue 5.

\section{CONTACT}

\author{
J.A. Romera Perez (TOS-MCT) \\ ESA/ESTEC \\ Keplerlaan, 1 \\ 2201 AZ Noordwijk \\ The Netherlands \\ Phone: +3171565 3979 \\ Fax: +31715656142 \\ e-mail: jromera@estec.esa.nl
}

\author{
J. Persson (MSM-MCE) \\ ESA/ESTEC \\ Keplerlaan, 1 \\ 2201 AZ Noordwijk \\ The Netherlands \\ Phone: +3171565 3814 \\ Fax: +31715656279 \\ e-mail: jpersson@estec.esa.nl
}

\section{J. Witt (MSM-MCE) \\ ESA/ESTEC \\ Keplerlaan, 1 \\ 2201 AZ Noordwijk}

The Netherlands

Phone: +3171 5654146

Fax: +31 715656279

e-mail: jwitt@estec.esa.nl 
Filename:

ices1.doc

Directory:

E:IuserslantoniolcofIICES

Template:

Title:

D:Microsoft OfficelTemplates\Normal.dot

Subject:

Author:

ES18

Keywords:

SAE International

Comments:

Creation Date: $\quad$ 06/03/00 09:59

Change Number: $\quad 42$

Last Saved On: $\quad$ 08/03/00 14:29

Last Saved By: ROMERA

Total Editing Time: $\quad 391$ Minutes

Last Printed On: $\quad$ 08/03/00 14:33

As of Last Complete Printing

Number of Pages: 11

Number of Words: 3,938 (approx.)

Number of Characters: $\quad 22,451$ (approx.) 